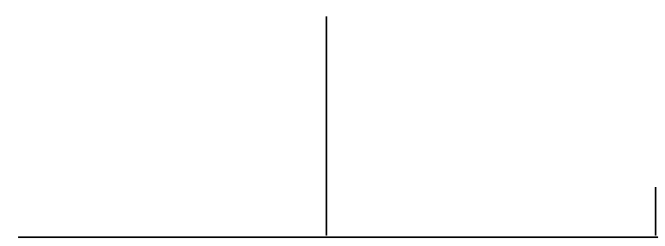

Rev. Latinoam. Psicopat. Fund., São Paulo, v. 14, n. 4, p. 599-610, dezembro 2011

\title{
Clivagem mortífera e guardiã de Eros*
}

Gabriela Maldonado Borges

Marta Rezende Cardoso

Nossa hipótese postula a clivagem como recurso funcional radical de sobrevivência psíquica ante uma experiência subjetiva traumática. Como estratégia de adaptação à realidade traumática, a clivagem é guardiã de Eros ou da sobrevivência psíquica, como se para sobreviver fosse necessário "matar" um pedaço de si. Nosso fio condutor será essa ambiguidade que situa o clivado entre Thanatos $e$ Eros.

Palavras-chave: Trauma, clivagem, Eros, Thanatos

* Este trabalho é um recorte específico da tese de doutorado de Gabriela M. Borges, "Neurose traumática: fundamentos e destinos". Esta pesquisa encontra-se em andamento desde Agosto de 2007, no Programa de Pós-Graduação em Teoria Psicanalítica da Universidade Federal do Rio de Janeiro - UFRJ (Rio de Janeiro, RJ, Br), sob a orientação da professora doutora Marta Rezende Cardoso e subvencionada com recursos da CAPES - Coordenação de Aperfeiçoamento de Pessoal de Nível Superior (Brasília, DF, Brasil).

Parte do presente estudo foi apresentada no IV Congresso Internacional de Psicopatologia Fundamental e X Congresso Brasileiro de Psicopatologia Fundamental, em Curitiba, no dia 7 de setembro de 2010. 


\begin{abstract}
A hipótese que norteia a reflexão que se segue postula a clivagem como recurso funcional radical de sobrevivência psíquica ante a vivência de uma experiência subjetiva traumática. Como estratégia de adaptação à realidade traumática, a clivagem é guardiã da vida ou da sobrevivência psíquica, mas tudo se passa como se, para sobreviver, fosse necessário "matar" um pedaço de si. Assim, a clivagem revela a presença de um trabalho ativo, permanente e radical de autoconservação da vida psíquica, o qual, paradoxalmente, opera por meio de um corte na subjetividade, corolário da imposição de amortecimento psíquico.

Vamos abordar o mecanismo da clivagem visando demonstrar como esta defesa extrema e paradoxal pressupõe a utilização de recursos psíquicos operando num registro que se situa, em última análise, além dos princípios de prazer e de realidade (Freud, 1920). Desejamos sustentar que a possibilidade da clivagem também põe em jogo uma função de autoconservação psíquica do ser diante do mortífero do trauma.

Guiados por essa perspectiva, podemos avançar que pelo menos três correntes simultâneas de fenômenos distintos, mas inter-relacionados, são acionadas no processo da clivagem: um ato de renegação (Verleugnung) e uma cisão do ego (Spaltung), mas cujo pano de fundo é um processo de amortecimento da memória e da afetividade, o qual iremos considerar como uma espécie de congelamento do afeto, fenomenologicamente semelhante a um processo de "desafetação". Nosso fio condutor será justamente essa ambiguidade que marca o clivado, situado entre a vida e a morte.
\end{abstract}

\title{
Verleugnung
}

O termo alemão Verleugnung comporta ambiguidade, uma vez que designa a tentativa de renegar ou de desmentir algo afirmado antes. Através do acionamento deste mecanismo, duas realidades paralelas e contraditórias vêm estabelecer-se na vida psíquica. "Fre- 
quentemente é como se o sujeito soubesse que aquilo que é rejeitado existe, mas continua a negar sua existência ou presença" (Hanns, 1996, p. 304). Neste sentido, o mecanismo da clivagem - descrito por Freud (1923) como defesa pela qual o indivíduo se recusa a reconhecer a realidade de uma percepção negativa - tem que ser constantemente reeditado, pois aquilo que é renegado ou desmentido não é eliminado do psiquismo, ao contrário, permanece existente, fazendo exigências a partir de seu lugar de renegado.

Essa dupla operação de reconhecimento e de recusa foi mais claramente delimitada por Freud em seu artigo sobre o fetichismo (1927), por meio da análise da questão da Verleugnung. Esta caracteriza a defesa posta em marcha no fenômeno do fetichismo, assim como nas patologias perversas em geral. Tratar-se-ia de operação paradoxal e bizarra na qual, ante o terror gerado pelo reconhecimento da realidade da diferença dos sexos, o ego, por recusa peremptória da realidade da castração, erige um "substituto": o fetiche. Para Freud, este último seria o representante e o produto de algo que foi rejeitado, instalando, assim, uma clivagem no interior do ego.

$\mathrm{O}$ tema do fetichismo traz importantes esclarecimentos para o nosso estudo, já que o conceito de clivagem do ego em Freud é tributário dessa teorização que ele desenvolve no artigo de 1927. Além disso, Freud nos alerta que "quando o fetiche é instituído, ocorre certo processo que faz lembrar a interrupção da memória na amnésia traumática" (p. 182). Nesse fenômeno o interesse do indivíduo é interrompido, e a última impressão que precede o vivido traumático fica retida qual um fetiche. Nesse contexto, a clivagem no eu corresponde à outra face de um processo de renegação, o qual estaria na origem da patologia fetichista e, igualmente, no cerne dos transtornos de memória observáveis nos quadros de neurose traumática. São estes, aliás, que constituem a base de nossa reflexão no presente trabalho.

Sobre a aproximação entre fetichismo e clivagem pós-traumática, René Roussillon (1999, p. 27-31) oferece reflexão esclarecedora. No rastro de Freud, ele vem acrescentar que o fetiche seria um atributo mágico que protegeria o sujeito do retorno de experiências que ficaram clivadas por não poder ter sido simbolizadas. O fetichismo comportaria, dentre outros quadros patológicos, aquilo que o autor considera "ligações primárias não simbólicas", as quais consistem num conjunto de respostas erigidas pelo ego contra o retorno de experiências traumáticas primárias que ficam clivadas no psiquismo, em função de seu caráter intraduzível.

"A solução fetichista sutura, assim, a clivagem anterior que afetou a subjetividade; ela produz um representante-representativo que liga e cicatriza a clivagem, mas resulta daí a renúncia ao caráter metaforizante da simbolização psíquica" (Roussillon, 1999, p. 30; tradução nossa). 


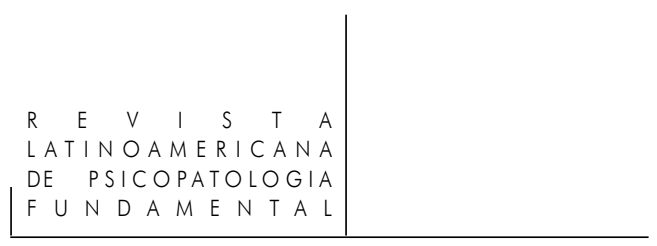

A perspectiva de análise aberta pelo estudo do fetichismo inaugura complexa rede de questões envolvendo o mecanismo da renegação da realidade traumática e a tentativa de circunscrevê-la e integrá-la a um contexto representativo. Diante de uma "realidade impossível", o recurso da renegação parece ser uma saída que não deixa, porém, de apontar para a direção da autoconservação psíquica, atestando, por outro lado, a existência de um "corpo estranho" no psiquismo. Este aponta justamente para a existência de elementos traumáticos que não puderam ingressar num circuito representacional, permanecendo no psiquismo na posição de "enclave".

É dessa posição que nos fala Luís Claudio Figueiredo (2008), quando propõe traduzirmos a Verleugnung freudiana por "desautorização". Para o autor, o que está na base desta operação é a desautorização de um dos aspectos da realidade percebida. Porém, o que é desmentido ou desautorizado não é a percepção em si mesma, mas a própria capacidade desta de transitar numa via "significante" ou de sentido. Nos termos de Figueiredo, o que acontece com a percepção sobre a qual incide a Verleugnung é que ela não tem "autoridade" para ensejar outras percepções. Assim, a impressão submetida a essa operação, permanece numa posição de enclave psíquico, pois "é mantida isolada do processo perceptivo e das suas conexões naturais com os processos mnêmicos e de simbolização" (p. 60). Privadas da possibilidade de inscrição nas redes associativas, as percepções desautorizadas são preservadas no psiquismo com todo o seu potencial traumático, num estado de "quase coisas", posto que ao serem dissociadas das trilhas associativas, ficam impedidas de transitar no campo do sentido.

Neste ponto somos conduzidos à noção de "inconsciente invalidado", muito fecunda para trabalharmos a questão da clivagem traumática, considerando-se que esta diz respeito, precisamente, à existência de estados afetivos não integráveis pela subjetividade (Stolorow \& Atwood, 1993, apud Figueiredo, 2008, p. 26, 62). De acordo com a análise de Figueiredo sobre o artigo de Stolorow e Atwood, o inconsciente invalidado abarca experiências afetivas muito intensas que não foram validadas ou autorizadas pelo contexto social. De forma resumida, tratar-se-ia de experiências afetivas muito intensas que não puderam ingressar numa cadeia representacional por nunca terem evocado resposta do entorno capaz de acolher e articular simbolicamente essas intensidades. Forma-se, então, no psiquismo, uma espécie de compartimento quase "coisificado", contendo elementos dissociados e potencialmente traumáticos, aos quais o autor se refere como "quase coisas", pela impossibilidade de estabelecerem conexão a um campo de "significância".

A noção de inconsciente invalidado pode ser ainda complementada por outra contribuição de grande relevância para os nossos propósitos, e que nos é oferecida por Marie-Françoise Laval-Hygonenq (1999). Investigando a importante e 
árida questão da sobrevivência nos campos de concentração, essa autora, ainda que sem fazer referência direta à noção de inconsciente invalidado, fala-nos de um inconsciente clivado do ego. Mostra que num ambiente onde a morte é onipresente, o acesso ao inconsciente pode representar ameaça à sobrevivência, uma vez que "ele não conhece a morte" (p. 44; tradução nossa). Desde Freud (1915) sabemos que a tarefa de sobreviver é da competência do ego, pois além de não haver representação de morte no inconsciente, "o id desconhece a solicitude acerca da garantia de sobrevivência" (Freud, 1940a, p. 227).

Desdobrando essa tese, Laval-Hygonenq (1999) sustenta que nos campos de concentração, assim como nas situações onde há ameaça à vida, o psiquismo tende a operar em regime de funcionamento atrelado ao registro do "atual", o que se traduz por superinvestimento da consciência e da atenção, em resposta à exigência de trabalho que a realidade traumática lhe impõe. Para que o psiquismo seja preservado do excesso quantitativo, os campos da consciência e da atenção se alargam: “... a consciência tenderia a se tornar agora uma qualidade permanente do psiquismo" (p. 43; tradução nossa), e o acesso ao inconsciente seria estritamente vigiado. Neste caso, a estratégia de adaptação à realidade traumática implica uma espécie de ruptura, de barreira ao inconsciente sistêmico, já que o acesso ao mesmo poderia tornar-se fatal. $\mathrm{O}$ investimento na realidade presente torna-se praticamente uma necessidade vital.

Baseados nessas proposições, temos cada vez maior conviç̧ão na hipótese segundo a qual o mecanismo de Verleugnung comporta uma dimensão de remanejamento psíquico, necessário à sobrevivência. Esse rearranjo ante à realidade traumática possui finalidade autoconservadora, o que nos faz lembrar da noção freudiana de "urgências da vida" (1950 [1895]), por seu caráter imperativo, inadiável, inescapável, além de revelar os paradoxais recursos a que o psiquismo apela para inventar novas estratégias de sobrevivência. Estas estariam, entretanto, situadas "além" dos princípios de prazer e de realidade.

Vale sublinhar que essa modalidade de resposta defensiva ao trauma não é dissociada do processo mais amplo da cisão (Spaltung). Ao contrário: trata-se de respostas defensivas relacionadas e complementares que revelam esforço radical de modificação ativa do funcionamento psíquico, testemunhando as imensas capacidades adaptativas do ser humano diante das "urgências da vida".

Segundo o nosso entendimento, a Verleugnung constitui um mecanismo de autoinvestimento, por se tratar de estratégia de sobrevivência egoica ante à realidade traumática mortífera, e que opera mediante a retirada dos investimentos da realidade, voltando-os para o eu, como tentativa de restauração narcísica. Trata-se de autoinvestimento paradoxal, contudo, pois o preço a ser pago pela sobrevida é o de uma amputação no ser. 


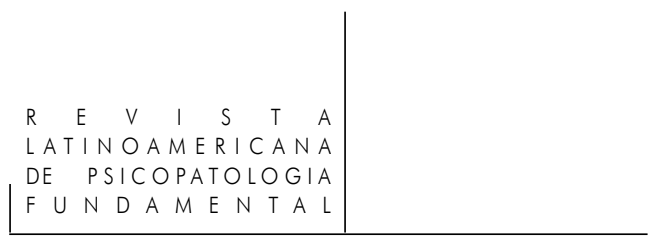

\section{Spaltung}

De acordo com Freud (1940b[1938]), o processo de clivagem traduz a coexistência no ego de "duas reações contrárias, ambas válidas e eficazes" (p. 309). Uma delas recusa a realidade (Verleugnung), a outra aceita-a, mas o ônus desse arranjo é um corte, "uma fenda no ego a qual nunca se cura, mas, ao contrário, aumenta à medida que o tempo passa" (Loc. cit.). Mostra Freud que a cisão do ego (Spaltung) em duas atitudes psíquicas coexistentes e contraditórias supõe a renegação da realidade (Verleugnung), sendo correlata do "desligamento" (1940a[1938]) de uma parte do ego em relação ao mundo externo. Esta defesa por desligamento, no entanto, nunca alcança êxito completo, pois a parte que veio a ser desligada continua eficaz, conduzindo a complicações na vida psíquica. Voltaremos mais adiante a este aspecto da questão.

Diferentemente do processo acima, descrito por Freud como divisão do ego, Roussillon se dedica a investigar um tipo de processo dissociativo, que irá designar como "clivagem ao ego". Tratar-se-ia, segundo ele, de um processo que divide a subjetividade entre uma parte representada e outra não representável, de maneira que o processo se dá como se o ego se clivasse de uma experiência subjetiva experienciada e, ao mesmo tempo, não vivenciada como sua experiência.

Partindo das proposições freudianas do "Esboço de psicanálise" (1940a[1938]), mas baseando-se igualmente nas formulações de Winnicott sobre os traumas precoces, Roussillon descreve essa clivagem ao ego como processo paradoxal de retirada de si, no qual o ego, para sobreviver à morte traumática, corta radicalmente de si próprio uma parte de sua vida subjetiva. Diante de uma situação extrema, precoce ou tardia, o ego se retira da experiência traumática, o que resulta, portanto, no surgimento de uma zona traumática clivada da subjetividade consciente no psiquismo. O que fica dissociado no psiquismo é uma parte da própria subjetividade, uma parte sem representação, retirada da experiência:

De um lado a experiência foi "vivida" e deixou "traços mnésicos" do que foi experienciado e, de outro lado, ela não foi vivida e apropriada como tal, (...), como diz Winnicott, ela não foi colocada na presença do ego, o que suporia que tivesse sido representada. (Roussillon, 1999, p. 20; tradução nossa)

Essa formulação estabelece nítida distinção entre clivagem e recalque. Como bem explicita Roussillon, a primeira seria uma defesa que opera por retirada da subjetividade, e não apenas por retirada da representação incompatível.

Este processo pode ser entendido como bifurcação do investimento narcísico em resposta à ameaça de aniquilamento traumático (Vertzman, 2002). Isso nos faz evocar as estranhas palavras de uma sobrevivente de campo de concentração, ao relatar num poema a sua sensação de desalojamento, ante as pergun- 
tas que lhe eram endereçadas sobre as mortes que vira: "E todo interrogatório é sobre fatos que aconteceram perto de mim, porém sem mim. Eu vi, como vou negar? Mas nem as testemunhas mais mentirosas são tão pouco confiáveis quanto eu" (Klüger, 2005, p. 252, grifos nossos).

Neste ponto, pensamos ser pertinente resgatar um rico artigo de Winnicott, de grande valia para aprofundarmos a ideia dessa dimensão paradoxal que, como temos procurado mostrar, seria própria da clivagem. Um dos paradoxos concerne ao fato de o ego nela se manter presente, mas, ao mesmo tempo, é como se ele não estivesse lá, seja porque "bateu em retirada", seja, simplesmente, porque ainda não estava lá. Referimo-nos aqui ao artigo de Winnicott (1963), "O medo do colapso".

Winnicott investiga as experiências traumáticas precoces, ocorridas antes de o indivíduo estar capacitado a articulá-las simbolicamente. Ele nos fala de um tipo de adoecimento cuja origem estaria em eventos acontecidos mas que, paradoxalmente, não teriam sido "vivenciados" e, portanto, não haveria o que lembrar, posto que "o paciente não estava lá" (p. 74). O que o autor propõe é que o paciente não estava lá porque tudo teria ocorrido num tempo no qual "o bebê ainda não separa o eu do não eu: isto não pode acontecer separadamente do estabelecimento do $e u$ " (ibid.). Nos termos de Winnicott: estas experiências agonísticas primitivas teriam ocorrido num tempo em que não existia ainda um $e u$ integrado capaz de apropriar-se delas como pessoais; num tempo "que precedeu o grau de maturidade que tornaria possível ao vazio ser experienciado" (p. 75). Diante dessa impossibilidade de integração, essas experiências destrutivas, próprias ao início da vida, não podem ser percebidas devido à imaturidade do ego. São, então, caracterizadas como "agonias impensáveis". Tratar-se-ia de eventos que nunca poderiam ser rememorados, mas apenas atualizados na transferência.

É sobremodo notável o avanço das proposições freudianas sobre o além do princípio de prazer que Winnicott promove, por meio dessas formulações, aprofundando-as. O que temos em mente é que a experiência de agonia impensável é, de fato, contígua à noção freudiana de desamparo (Freud, 1926), as duas noções estando referidas a estados afetivos que estariam além da capacidade de rememoração, dissociados, portanto, dos processos de pensamento. Prolongando a teoria freudiana do além do princípio de prazer, o que Winnicott denomina "impensável" não nos conduz ao campo do recalcado, com suas representações incompatíveis e saberes esquecidos. Diferentemente disso, ela nos introduz ao registro do "irrepresentável", ao que não encontra meios para ser inscrito nas cadeias de representação, e que irá também retornar, mas sob uma forma clivada dos processos simbólicos.

Guiados por essas noções, introduziremos, a seguir, o terceiro e último tópico de nossa reflexão.

Rev. Latinoam. Psicopat. Fund., São Paulo, v. 14, n. 4, p. 599-610, dezembro 2011 


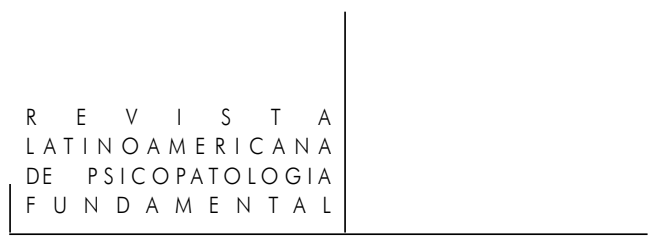

Amortecimentos...

Diante da impossibilidade de interiorização dos elementos traumáticos advindos de experiências-limite vividas, as impressões são registradas intensamente, mas numa quase ausência de si. Desse ponto de vista, o amortecimento da memória, fenômeno frequentemente observável nas amnésias traumáticas, diz respeito a uma operação de retirada da subjetividade, em estreita conexão com o que tentaremos aqui descrever como processo de amortecimento afetivo.

Para avançarmos na compreensão do que estaria em jogo nesse tipo de funcionamento psíquico, mencionaremos de forma muito breve e resumida a noção desenvolvida por Roussillon (1999) de "neutralização energética" (p. 25-27), e que expressa, com evidência, um processo de amortecimento afetivo e o consequente empobrecimento do ego, como estamos tentando descrever. Tratar-se-ia de tornar impossível o contato com a parte que foi clivada ao ego, pela total restrição aí implicada dos investimentos de objeto e de todas as relações que possam reativar a cena traumática e a clivagem que ali se produziu.

Nos termos do autor, a neutralização energética é uma espécie de defesa complementar à clivagem, cuja finalidade é impedir o retorno perceptivo da experiência que foi clivada anteriormente. Nesse contexto, tudo o que possa reinvestir o estado traumático, “(...) toda relação que possa gerar um retorno da falta será evitado ou 'congelado', todo engajamento será assim restringido e, com ele, a vida que vai junto" (p. 25; tradução nossa). Disso decorre empobrecimento subjetivo, estreitamento das possibilidades de investimento narcísico, já que parte considerável do psiquismo será empregada na tarefa de impedir o retorno do clivado, pelo desligamento afetivo, e que Roussillon aproxima das noções de funcionamento operatório e de depressão essencial.

Um estudo detalhado desses aspectos não caberia no escopo deste trabalho, mas importa para nós indicar que as estratégias em questão - de subtração dos investimentos afetivos e bloqueio das atividades representativas - já consistiriam, segundo Roussillon, em tentativas de ligação secundária à clivagem, ligação de aspectos que foram clivados e que ameaçam retornar com todo o seu potencial traumático. Para evitar a eclosão de mobilizações afetivas capazes de reativar a zona traumática clivada, lança-se mão, então, de tática defensiva radical que, de acordo com as indicações que fornecemos anteriormente, poderia ser entendida como processo de renegação do afeto, ou de "desafetação" generalizada. É como se o sujeito se clivasse de sua afetividade para não ser engolido por ela, numa espécie de desinvestimento protetor, conforme propõe Roussillon (p. 73).

Os aspectos clínicos ligados a estes mecanismos consistem em estados da mente "em branco", sem componentes afetivos, de dor ou sofrimento, ou seja, poder-se-ia acrescentar que corresponderiam à própria coisificação do nada no 


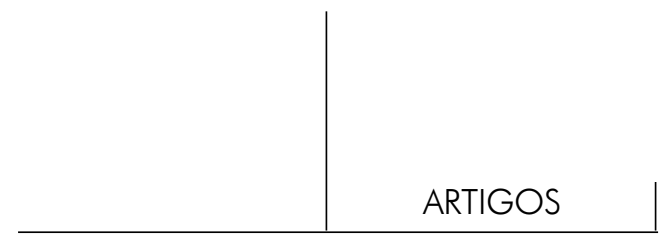

pensamento. Tendo no horizonte a metáfora do "gelo psíquico", pensamos que o que se apresenta nestes estados de "desafetação" é algo da ordem de um congelamento afetivo. Trata-se de uma modalidade de conservação do afeto em estado bruto, imóvel, "desautorizado", portanto, a transitar (Figueiredo, 2008, passim) pelas trilhas associativas do pensamento.

Tudo se passa como se diante da possibilidade do retorno doloroso dos elementos clivados, dos estados de desamparo (Freud, 1926) e de agonia impensável (Winnicott, 1963), houvesse dissociação entre o afeto e o sistema de pensamento. Esse mecanismo é uma última medida defensiva do ego contra a ameaça de desintegração e, simultaneamente, a própria atualização do traumático impensável.

Concluindo, a partir do que pudemos avançar nos três eixos analisados neste artigo, chegamos à ideia de um funcionamento psíquico de sobrevivência aparentado à rigidez dos mortos, resultante de um estado de desamparo "para além da falta e da esperança" (Roussillon, 1999, p. 19; tradução nossa). Tal suposição permite compreender o mecanismo de clivagem a partir de uma dinâmica hipercomplexa, que se desenrola no cerne do ser, entre Eros e Thanatos. Mas, invocando Freud (1930), nessa luta de Titãs, não se sabe ao certo quem será o vencedor.

Em vista dessas considerações, concluímos nossa reflexão sublinhando que a clivagem psíquica comporta dupla face, como vicissitude de Thanatos e Eros na vida psíquica. O mecanismo da clivagem revela ainda dupla função, já que se coloca, de uma só vez, como fundamento e destino do trauma. Isso vem reforçar a importância de uma análise cada vez mais aprofundada desse campo teórico-clínico. Avançar no desenvolvimento dessas ideias poderá certamente permitir maior compreensão e engajamento clínico mais depurado diante das obscuras questões que o sofrido estado psicopatológico da neurose traumática não cessa de endereçar ao psicanalista.

Agradecimento: Agradeço à minha orientadora prof. dra. Marta Rezende Cardoso, por ter contribuído generosamente para a realização deste trabalho, por meio da leitura dedicada, de sugestões precisas, além da preciosa troca de ideias e de afeto. Agradeço também a Pedro Henrique Bernardes Rondon pela revisão cuidadosa do texto.

\section{Referências}

FigueIREdo, L.C. Elementos para a clínica contemporânea. São Paulo: Escuta, 2008.

Freud, S. Edição Standard Brasileira das Obras Psicológicas Completas de Sigmund Freud. Rio de Janeiro: Imago, 1980. 24 vols.

Rev. Latinoam. Psicopat. Fund., São Paulo, v. 14, n. 4, p. 599-610, dezembro 2011 


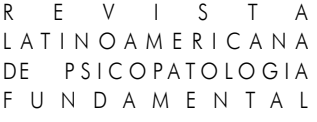

. (1895). Projeto para uma psicologia científica. In: Edição Standard Brasileira das Obras Psicológicas Completas de Sigmund Freud. Rio de Janeiro: Imago, 1980. V. 1, p. 381-400.

. (1915). Reflexões para os tempos de guerra e morte. In: Edição Standard Brasileira das Obras Psicológicas Completas de Sigmund Freud. Rio de Janeiro: Imago, 1980. V. 14, p. 311-339.

. (1920). Além do princípio do prazer. In: Edição Standard Brasileira das Obras Psicológicas Completas de Sigmund Freud. Rio de Janeiro: Imago, 1980. V. 18, p. $17-85$.

(1923). A organização genital infantil: uma interpolação na teoria da sexualidade. In: Edição Standard Brasileira das Obras Psicológicas Completas de Sigmund Freud. Rio de Janeiro: Imago, 1980. V. 19, p. 179-184.

. (1926). Inibições, sintomas e ansiedade. In: Edição Standard Brasileira das Obras Psicológicas Completas de Sigmund Freud. Rio de Janeiro: Imago, 1980. V. 20, p. 107-198.

. (1927). Fetichismo. In: Edição Standard Brasileira das Obras Psicológicas Completas de Sigmund Freud. Rio de Janeiro: Imago, 1980. V. 21, p. 179-188. . (1930). O mal-estar na civilização. In: Edição Standard Brasileira das Obras Psicológicas Completas de Sigmund Freud. Rio de Janeiro: Imago, 1980. V. 21, p. 81-171.

. (1940a[1938]). Esboço de psicanálise. In: Edição Standard Brasileira das Obras Psicológicas Completas de Sigmund Freud. Rio de Janeiro: Imago, 1980. V. 23, p. 168-246.

. (1940b[1938]). A divisão do ego no processo de defesa. In: Edição Standard Brasileira das Obras Psicológicas Completas de Sigmund Freud. Rio de Janeiro: Imago, 1980. V. 23, p. 309-314.

. (1950[1887-1902]). Extratos dos documentos dirigidos a Fliess. In: Edição Standard Brasileira das Obras Psicológicas Completas de Sigmund Freud. Rio de Janeiro: Imago, 1980.

Hanns, L. Dicionário comentado do alemão de Freud. Rio de Janeiro: Imago, 1996.

KLÜGER, R. Paisagens da memória: autobiografia de uma sobrevivente do holocausto. São Paulo: Editora 34, 2005.

LaVal-HygonenQ, M.F. Du fonctionnement psychique de survie dans l'univers concentrationnaire. In: Zaltzman, N. (dir.). La résistance de l'humain. Paris: PUF, 1999. p. 25-52.

Roussillon, R. Agonie, clivage et symbolisation. Paris: PUF, 1999.

Rev. Latinoam. Psicopat. Fund., São Paulo, v. 14, n. 4, p. 599-610, dezembro 2011 
VertzMAn, J.S. O observador do mundo: a noção de clivagem em Ferenczi. Ágora: estudos em Teoria Psicanalítica, Pós-graduação em Teoria Psicanalítica, Rio de Janeiro, v. 5, n.1, jan.-jun. 2002.

Winnicott, D.W. (1963). O medo do colapso. In: Winnicott, C.; Sheperd, R.; Davis, M. (Orgs.). Explorações psicanalíticas. Porto Alegre: Artmed, 1994. p. 70-76.

\section{Resumos}

(Deadly cleavage and the guardian of Eros)

Our hypothesis is that cleavage can be seen as a radical functional resource for psychic survival in the wake of traumatic subjective experiences. As a strategy for adapting to traumatic reality, cleavage is the guardian of Eros, which might also be called psychic survival, as if, to survive, one must "kill" a part of oneself. Our guiding principle is this ambiguity that places cleavage between Thanatos and Eros.

Keywords: Trauma, cleavage, Eros, Thanatos

(Clivage mortifère et gardienne d'Éros)

Notre hypothèse pose le clivage comme une ressource fonctionnelle radicale pour la survie psychique face à une expérience subjective traumatique. Comme stratégie d'adaptation à la réalité traumatique, le clivage est le gardien d'Éros ou de la survie psychique, comme si pour survivre il aurait fallu "tuer" une partie de soi. Notre fil conducteur sera cette ambiguïté qui situe le clivage entre Thanatos et Éros.

Mots clés: Traumatisme, clivage, Éros, Thanatos

(Escisión mortífera y guardiana de Eros)

Nuestra hipótesis postula la escisión como un recurso funcional y radical de supervivencia psíquica frente a una experiencia subjetiva traumática. Como estrategia de adaptación a la realidad traumática, la escisión es guardiana de Eros o de la supervivencia psíquica, como si para sobrevivir fuera necesario "matar" a una parte de si-mismo. Nuestro hilo conductor será la ambiguedad que sitúa lo escindido entre Thanatos y Eros.

Palabras claves: Trauma, escisión, Eros, Thanatos.

Citação/Citation: Borges, G.M.; CARDoso, M.R. Clivagem mortífera e guardiã de Eros. Revista Latinoamericana de Psicopatologia Fundamental, São Paulo, v. 14, n. 4, p. 599-610, dez.2011.

Rev. Latinoam. Psicopat. Fund., São Paulo, v. 14, n. 4, p. 599-610, dezembro 2011 
Editor do artigo/Editor: Prof. Dr. Manoel Tosta Berlinck

Recebido/Received: 6.11.2010 / 11.6.2010 Aceito/Accepted: 23.1.2011 /1.23.2011

Copyright: (C) 2009 Associação Universitária de Pesquisa em Psicopatologia Fundamental/ University Association for Research in Fundamental Psychopathology. Este é um artigo de livre acesso, que permite uso irrestrito, distribuição e reprodução em qualquer meio, desde que o autor e a fonte sejam citados/This is an open-access article, which permits unrestricted use, distribution, and reproduction in any medium, provided the original author and source are credited.

Financiamento/Funding: Esta pesquisa é financiada pela CAPES - Coordenação de Aperfeiçoamento de Pessoal de Nível Superior/This research is funded by the CAPES - Coordenação de Aperfeiçoamento de Pessoal de Nível Superior.

Conflito de interesses/Conflict of interest: As autoras declaram que não há conflito de interesses/The authors declare that has no conflict of interest.

\section{Gabriela Maldonado Borges}

Psicanalista; Mestre em Psicologia Clínica pela Pontifícia Universidade Católica do Rio de Janeiro - PUC-RJ (Rio de Janeiro, RJ, Br); doutoranda do Programa de Pós-Graduação em Teoria Psicanalítica da Universidade Federal do Rio de Janeiro - UFRJ (bolsista da CAPES) (Rio de Janeiro, RJ, Br); orientanda da profa. dra. Marta Rezende Cardoso e integrante do grupo de pesquisa: "A violência pulsional na clínica contemporânea: fundamentos e vicissitudes".

Avenida Macuco 550/93 - Indianópolis-Moema

05423-001 São Paulo, SP, Br

Fone: (11) 5083-0480 / (11) 8856-9748

e-mail: maldonadogabriela@yahoo.com.br

\section{Marta Rezende Cardoso (03/2011)}

Psicanalista; doutora em Psicopatologia Fundamental e Psicanálise - Universidade Denis Diderot - Paris 7 (França); professora Associada do Instituto de Psicologia da Universidade Federal do Rio de Janeiro - UFRJ (Rio de Janeiro, RJ, Br) - (Programa de Pós-Graduação em Teoria Psicanalítica); membro da Associação Universitária de Pesquisa em Psicopatologia Fundamental (São Paulo, SP, Br); pesquisadora do CNPq (bolsa de produtividade em pesquisa) (Brasília, DF, Br).

Rua Gustavo Sampaio, 710/1805

22010-010 Rio de Janeiro, RJ, Brasil

Fone: (21) 2543-8630

e-mail: rezendecardoso@ig.com.br rezendecardoso@gmail.com 